\title{
The Design and the Process Technology of a Rotational Mold
}

\author{
Alina Bianca Pop ${ }^{1}$, Gheorghe Ioan Pop ${ }^{2}$, and Mihail Aurel Țîțu ${ }^{3, *}$ \\ ${ }^{1}$ SC TechnoCAD SA, VasileAlecsandri no. 72, code 430351, Baia Mare, România \\ ${ }^{2}$ SC UNIVERSAL ALLOY CORPORATION EUROPE SRL, 244A, Principală Street, Dumbrăvița, \\ România \\ ${ }^{3}$ Lucian Blaga University of Sibiu, Victoriei Street no. 10, code 550024, Sibiu, România
}

\begin{abstract}
The present paper highlights a series of introduction aspects of the rotational system for slush plastic casting, which are the characteristic elements of this fabrication technology and which consists of the rotational molding. Also, the structure of a rotational mold and the methods used to obtain the mold, are presented. The purpose of this research is to describe the parametric design of a rotational mold and its fabrication process. The research method used to accomplish this purpose consist of the CAD Modelling specific software utilized to carry out the parametric design of the rotational mold. After the parametric design it was adopted the manufacturing technology of the mold, using a CAM specific software. In the final part of the research a few important conclusions were drawn from the bibliographical study and from personal convictions.
\end{abstract}

\section{Introduction}

The molding is the process of hot or cold plastic deformation where the material is required to take the form and dimensions of the cavity provided in the tool according to the configuration of the parts to be executed. The process applies to the machining of parts of various sizes and complex configuration, in small series production and mass [1].

The rotational molding is a unique process being increasingly applied, which allow the use of geometries and materials adapted to personal needs. [2]. The rotational molding is betters then other tooling methods in regard to low prices, the profitableness, and the piece dimensions which can be manufactured. Many times, the products mated by rotational molding represent a replacement with a less weight for the products usually used. [3, 4]. Technology has been improved, particularly in process control, materials used, and mold manufacturing. The high degree of automation of machines and the ever-increasing range of raw materials available allows the rotary molding process to address the most diverse applications; from small ones, such as plastisol syringes, to 87.720 liters of polyethylene containers [5].

Although the rotational molding concept is older than 150 years, the production of coreless pieces for diverse applications (like the play equipment, furniture, tanks, etc.) is

*Corresponding author: mihail.titu@ulbsibiu.ro 
used by along the last 50 years. [6]. Starting with the 1990 s, the production of rotational molds at industrial level increased each year by a percentage of 10 to $15 \%$ [7-10]. In general, the raw material used in rotational molding consists of crystalline thermoplastic materials such as: polyethylene, polypropylene, nylon, polyethylene terephthalate, vinyl polychloride, polycarbonates - which are amorphous thermoplastic materials or polyurethanes - which are thermosetting. In addition to those mentioned in the category of plastic materials used in the rotary molding process are included: polyethylenes - ULDPE, LDPE, LLDPE, MDPE, XLPE and HDPE; vinyl acetate and ethylene - EVA; polyvinyl chloride - PVC; polyamide (PA) "nylon" (PA6; PA11; PA12); polypropylene copolymer; polyester elastomer; polycarbonate - PC; ethylene butylacetate - EBA. The optimal temperatures to which plastic materials may undergo differ according to their nature, as shown in Figure 1.

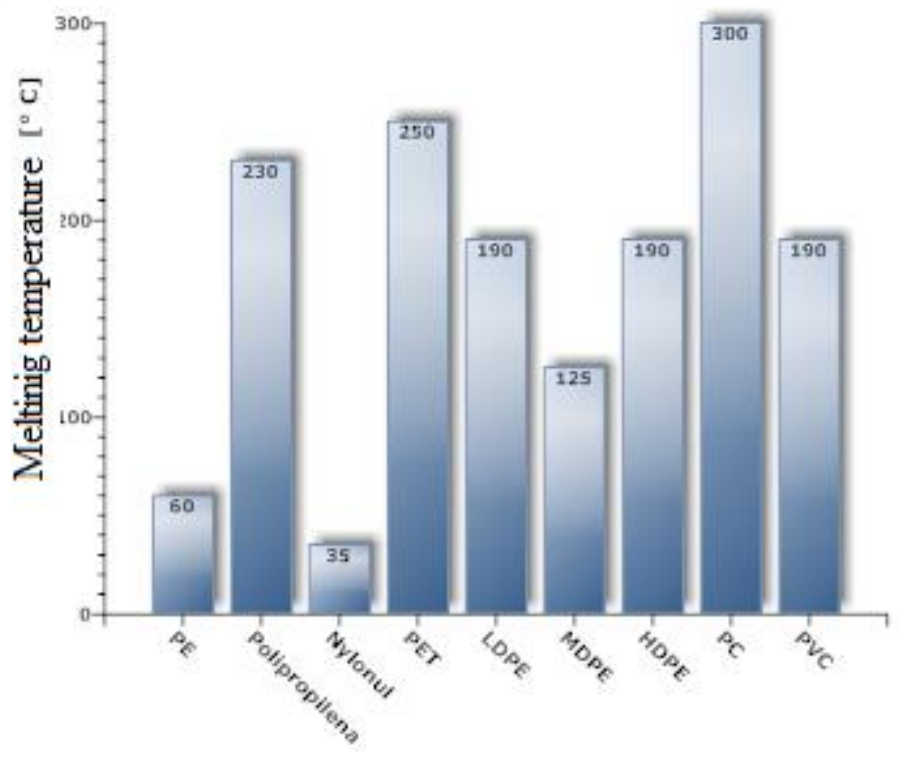

Fig. 1. Melting temperatures of plastics.

The plastic materials are used in every parish and the performance of this ingress in almost parish is owing to its unequalled properties. The plastic materials are stainless, electro insulating, they have low weights, they have good mechanical properties, low prices, they have a good looking, these materials can be mechanical manufactured on a traditionally way, also by specific process as like injection process, electroforming, galvanization, allowing on this way the material to take the look desired by the designer.

The most important process for pieces manufacture of plastic materials is: the blow forming process; the rotational molding; the injection process; the calendar process; the extrusion process; the thermoforming; the reduction (compression) process; the expansion process.

\section{The rotational molding technology for parts without core}

The rotational molding process allows the obtaining of parts without core by plastic materials. This process needs four basic elements without which the process cannot take place: the machine; the mold; the row material and the machine man.

The rotational molding is made of four phases, whose sequence defines the molding cycle: the row material (plastic material - powder, granules or in liquid form); heating the 
mold with the raw material in an oven (the operation is carried out at high temperatures); cooling the mold with the feedstock in a cooling chamber (with water, air, or a combination of air and water) and discharging the mold. The particularity of this technology is the permanently rotation of the mold with a low speed by two axes: -the first and the principal rotation is the faster and the second rotation is slower.

Due to the two movements and as the heat is transmitted through the walls, the plastic penetrates into all the internal holes of the mold and is completely melted, covering the entire surface thereof. This is due to the adhesion of the polymer to the mold walls and not to the centrifugal force. The final piece results from the gradual melting of the polymer. The role of gradual cooling is to lower the temperature to the point of crystallization or solidification of the material introduced into the mold. Biaxial rotation prevents bending of the material. Once the material is cooled and solidified, the mold is moved to the discharge station. Here the mold is opened and the finished product is extracted and the cycle resumed with the mold loading.

\section{The parametric design of a rotational mold using the CAD application CATIA V5}

Designing form and dimensions of part, is a virtual modeling process (3D and 2D) of it, using a variety of CAD applications, according to the requirements of the beneficiary and the possibility of it realization. The part can have a complex form, which requires 3D modeling and analysis of the part areas so technically and esthetically.

The parametrical design of molds in CATIA V5 R17 follows the next steps (figure 2): designing the shape and dimensions of the part to be processed by molding; designing the molds following the form and dimensions of part and the jig design on the rotational machine arm.

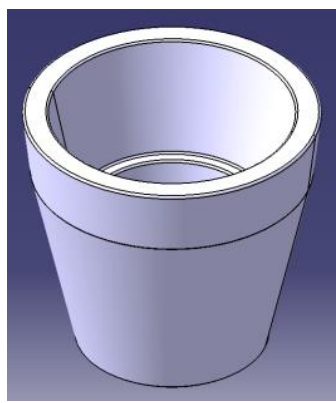

a)Parametric design of the piece

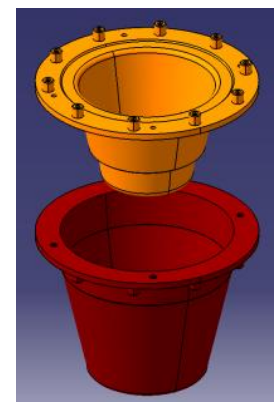

b)Parametric design of the mold

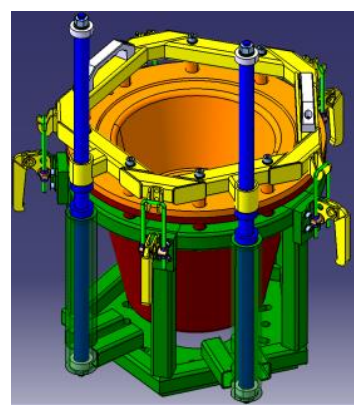

a)Parametric design of jigs

Fig. 2. Parametric design of the assembly.

\section{The mold manufacturing simulation process using the POWERMILL CAM application}

Computer-aided machining (CAM) is basically a software tool designed to support engineers and machinists in the manufacturing process of a wide variety of workpieces. CAM is a tool that allows the use of $3 \mathrm{D}$ models based on computer aided design (CAD). The CAM application chosen for simulation is POWERMILL. The CNC machine chosen to manufacture the mold is OKUMA MU-400VA. An AlCu6Mn aluminum die casting of $\varnothing 500 \times 381 \mathrm{~mm}$, is selected. By using 3D simulation, PowerMILL automatically checks the tool paths both in roughing and finishing to avoid tool-style collisions, plus allowing this 
toolbar check. In addition to these checks, the user has the ability to simulate the machining path with the real image of what will happen to the machine, PowerMILL guaranteeing that what you see through the simulation will just happen to the machine. Simulation is also helpful in viewing the movement directions of the cutting tool in order to estimate the point at which the cutting tool will arrive at a given time. Figure 3 shows a diagram with the links between the steps required to make a rotational mold using CAD tools (CATIA V5 application) and CAM tools (PowerMILL application).

$\mathrm{CAD}$

Parametric design of the mold

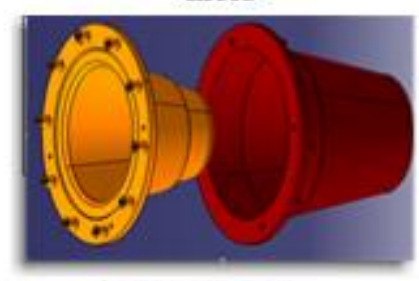

CATIA V5
CAM

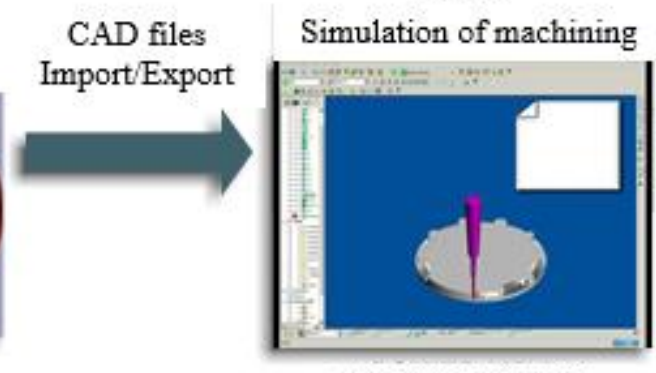

POWERMILL

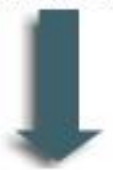

Implementing the program

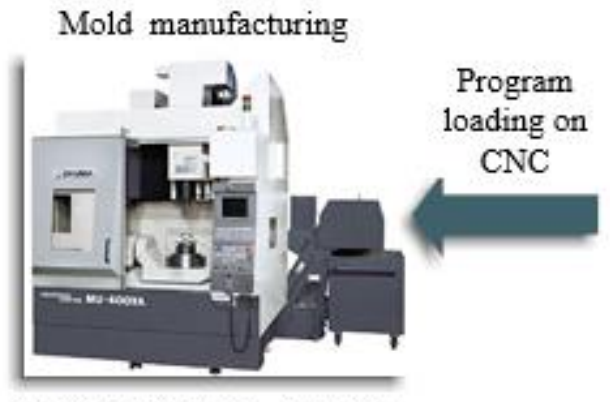

OKUMA MU-400VA

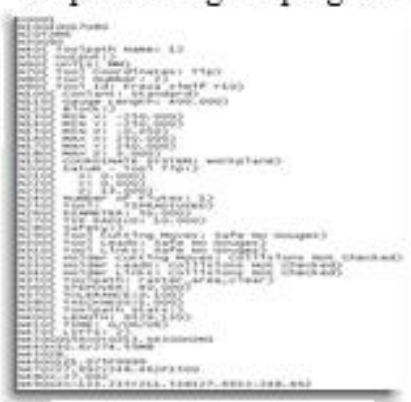

POWERMILL

Fig. 3. Steps for making the rotational mold

\section{Optimization of the cutting regime with POWERMILL-CAM application}

Optimizing the cutting regime in this research involves the machining of a surface of the external mold using some deductions based of direct observations (track, tool type and diameter, cutting speed and depth) aiming at the minimum required surface quality $\left(\mathrm{R}_{\mathrm{a}}\right)$ through technology and minimal base time.

Thus, in order to carry out the research the chosen tool type is R218.20-2.0050.3P70.120 with a diameter of $50 \mathrm{~mm}$, the cutting speed $\left(\mathrm{v}_{\mathrm{c}}\right)$ is $670 \mathrm{~m} / \mathrm{min}$, and the cutting depth $\left(a_{p}\right)$ varies with the values of: 10 and $15 \mathrm{~mm}$.

Next, two tool paths will be chosen to make a comparison. So, using the first Raster AreaClear Model, in this case the tool, performs a zigzag movement, processing the workpiece until it encounters the surface of the previously loaded track in the program. Once it comes into contact with the work surface, it leaves it only after finishing the work. 
At the end of a work trajectory there is a movement along the positioning direction until the position for the next pass is determined.

Table 1. The data obtained for the two established routes.

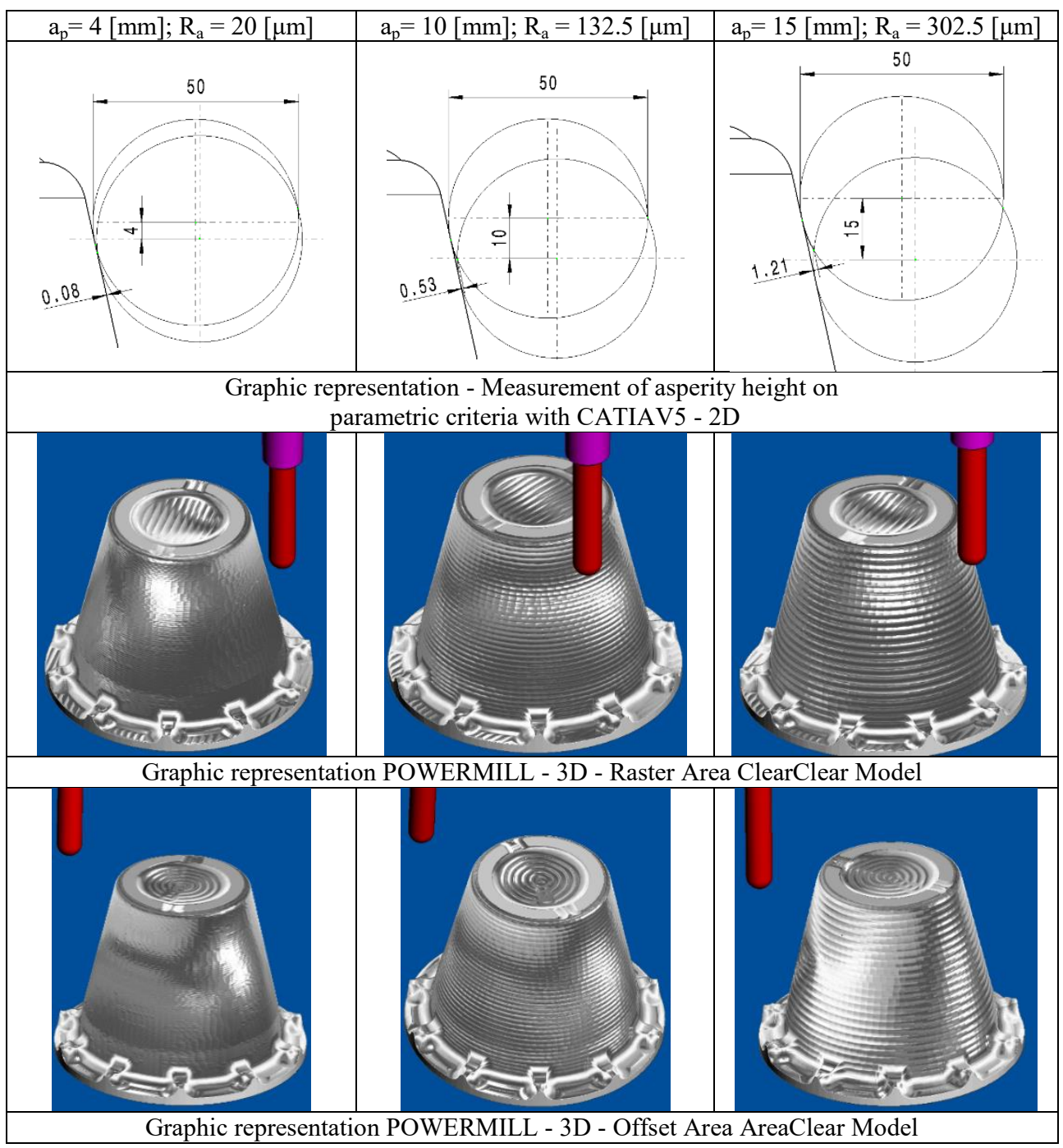

In the case of the Offser AreaClear Model, the tool performs a machining motion in which it remains in permanent contact with the work surface, as with the zigzag strategy, with the difference that there is no positioning movement for the next pass, this being transformed into a working motion, after the positioning direction. There is an approximately spiral motion on the surface of the piece. The sense of movement can be from the outside to the inside or from the inside to the outside. With the same cutting points, the same roughness and the same graphical representations of the measured elevations of the asperities on the parametric criteria with CATIAV5 - 2D, Table 1 presents the offset AreaClear Model data as well.

The processing times obtained in these cases are shown in Figure 4. 


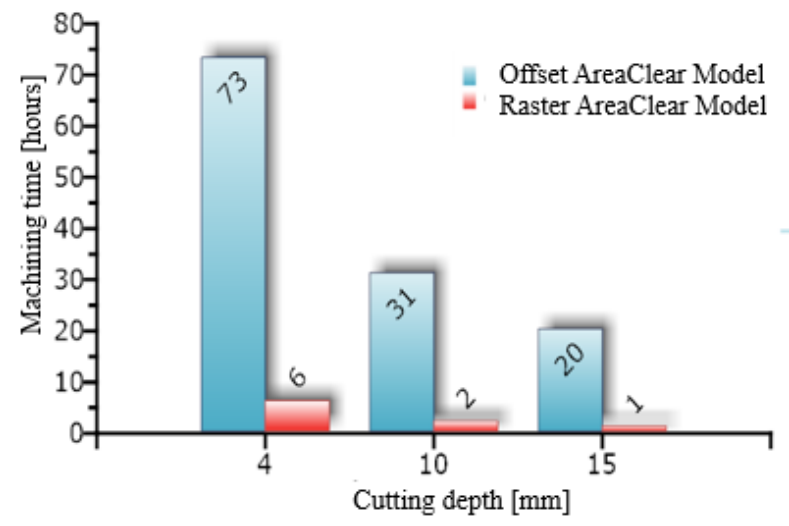

Fig. 4. Variation of machining time according to the cutting depth and machining path of the tool.

\section{Conclusions}

As a conclusion of this study thanks to the uninterrupted cutting process, choosing the Offset AreaClear Model tool path, ensures maximum productivity - and the processing time is minimal. Mold making using CAD - computer aided design is a modern method. To simplify the programming process, the CAM system can be used.

CAM is a software running on a computer (generally a PC) that helps the CNC programmer in the programming process. At present, $\mathrm{CNC}$ machines are found in almost all phases and operations in different manufacturing areas, regardless of whether the machined object is made of metallic materials, plastics or different wood essences.

\section{References}

1. R.J. Crawford, M.P. Kearns, Practical Guide to Rotational Moulding (Rapra Technology Limited, UK, 2003)

2. P. Nugent, Applied Plastics Engineering Handbook, Processing, Materials, and Applications (volume in Plastics Design Library, 2nd Edition, 2017)

3. S.B. Tan, Accelerated Cooling of Thermoplastics in Rotational Moulding (Ph.D. Thesis in Mechanical and Aerospace Engineering, Queen's University Belfast, UK, 2010)

4. M. Spencer, M.P. Kearns, Rotational Molding News, 01/03, 6 (2001)

5. M.P. McCourt, M.P. Kearns, Proc. Pan-European Rotomoulding Res., 4, 6 (2009)

6. B. I. Chaudhay, E. Takacs, J. Vlachopoulos, Processing Enhancers for Rotational Molding of Polyethylene, Po. Eng. Sci. 41, 1731 (2001)

7. Gh. Rusu, M. Rusu, E. Rusu, A. Stoleriu, C. Teaca, Polym. Plast. Technol. Eng. 39, 233 (2000)

8. A. Garg, F.P.C. Gomes, P. Mhaskar, M.R. Thompson, Model predictive control of uniaxial rotational molding process, Computers \& Chemical Engineering 121 (2019)

9. A. Ianakiev, K.K. Lim, Ann. Tech. Conf.-ANTEC 5, 2737 (2007)

10. R.M. Khouri, Reducing Cycle Times in Rotational Moulding of Plastics: A Theoretical and Experimental Analysis (Ph.D. Thesis in Mechanical and Manufacturing Engineering, Queen's University Belfast, UK, 2004) 